\title{
Expression of Pain by Children and Its Assessment in Kuwait
}

\author{
Dhari Alwugyan Faisal Alroumi Mohammad Zureiqi \\ Department of Community Medicine and Behavioral Sciences, Faculty of Medicine, Health Sciences Center, \\ Kuwait University, Kuwait
}

\author{
Key Words \\ Pain in children - Pain assessment - Pain expression - Pain \\ scale
}

\begin{abstract}
Objective: To study the ability of children to describe, localize, and assess the intensity of their current pain and to compare their evaluation with those of their parents. Subjects and Methods: A cross-sectional survey was conducted among 281 native Arabic-speaking children, 6-12 years old, presenting with acute pain to the emergency room accompanied by at least one adult. Data were collected in Al-Amiri, Mubarak Al-Kabeer, Al-Adan, Al-Farwaniya and Al-Jahra hospitals by interviewing children and by giving a self-administered questionnaire to the accompanying adult. Intensity of pain was measured using the Faces Pain Scale. Children described their pain using 23 verbal expressions. Results: The most frequently used words to describe pain were 'it hurts' and 'it hurts a lot' followed by a 'burning sensation'. The most common sites of pain were the abdomen, pelvis, and loin. Intensity of pain was associated with birth order and higher number of siblings, lower number of previous pain episodes, lower family income, and lower educational level of the mother. No relationship was found between self-reported pain intensity and nationality, area of residence, gender, or father's educational level. There was no agreement in pain intensity assessment between parents and children. Conclusion: The study shows that children were able to ver-
\end{abstract}

(C) 2007 S. Karger AG, Basel

1011-7571/07/0167-0021\$23.50/0

Fax +4161306 1234

E-Mail karger@karger.ch

www.karger.com
Accessible online at: www.karger.com/mpp balize their current pain, its intensity and site. The Faces Pain Scale was easy to administer and useful in measuring the intensity of pain.

Copyright $\odot 2007$ S. Karger AG, Basel

\section{Introduction}

Pain is a multidimensional phenomenon. It refers, in general, to an unpleasant, distressful and uncomfortable feeling [1]. Accurate measurement of pain in children is very important in order to evaluate the clinical picture and efficacy of treatment [2]. Physiological and psychological factors and past experience are the main parameters by which an individual is able to evaluate pain [3]; therefore, growth, development and culture play an important role in how pain is described or expressed [1].

It is common practice for health professionals to evaluate the child's pain based on information given by adults, ignoring the child's evaluation of pain [3]. School-aged children (7-11 years of age) have language skills, which they can use to describe different quantitative and qualitative components of pain [3]. Children have the ability to describe the location, the intensity, and the quality of the pain in their own words [1].

In spite of pain having the same physiology, the meaning of pain varies according to culture [1], which has an effect on behavior and the way pain is perceived [2]. Studies from Taiwan [1] and Finland [3] tend to focus on the 
way in which children can evaluate and express their pain experience in their own words. Immature language skills may make expression of pain by children more difficult to assess [3].

The limited ability of a child to describe the level of pain and fear of pain-relieving interventions may cause a lack of acknowledgment of regarding the level of pain [4]. In addition to the cognitive immaturity of children, fear and anxiety associated with past experience of pain can lead to some difficulties in the assessment of pain in children [5].

The aim of this study was to investigate pain perception and expression in Arabic-speaking school-aged children. The red-colored Faces Pain Scale of Wong and Baker [6] was used because its validity, reliability and practicality had been authenticated in previous studies $[2,7$, 8].

\section{Subjects and Methods}

A cross-sectional survey was conducted of 6- to 12-year-old children presenting with an acute pain episode to the pediatric emergency room of 5 major general hospitals in Kuwait, i.e. AlAmiri, Mubarak Al-Kabeer, Al-Adan, Al-Farwaniya, and Al-Jahra. The participants were native Arabic-speaking children, each accompanied by an adult. Mentally retarded children as well as children with severe pain were excluded because of communication problems.

Of 286 accompanying adults, 281 agreed to take part in the study. Of the 5 that refused, 4 were in a hurry and the fifth refused because she was a female and the data collector was a male. Hence, the study was conducted on 281 children. Permission to conduct the study was obtained from the Ministry of Health and the Head of each Emergency Room Department of the participating hospitals.

\section{Research Instruments}

An interview was conducted with the child and the information was recorded by the data collector. Four questions were directed to the child by the data collector: the first contained a body diagram for identification of the site of most pain; the second assessed the ability of the child to localize the site of pain; the third was an open-ended question asking for a verbal description of current pain, and the fourth covered self-assessment of pain intensity. The red-colored Faces Pain Scale of Wong and Baker [6] translated into Arabic was used in this study. The expression of each colored face corresponded to each grade of pain, starting from a smiling face representing zero pain to a crying face representing 10, the most intense pain.

A self-administered questionnaire with an informed consent was given to the adult. The questionnaire consisted of 11 questions: age, sex, nationality, number of siblings and birth order of the interviewed child, level of education of both parents and total family income per month. Further questions covered the child's past experience of pain (number of painful episodes in the last year) and the adult's assessment of the child's current pain intensity on a visual analogue scale, which was graded from 0 to $10-$ where 0 was 'no pain' and 10 was the 'worst pain'. A short explanation was given of the visual analogue scale in order to make it more understandable.

\section{Data Collection}

Data collection lasted 7 days in the 5 hospitals. Each hospital was covered equally, 4 times per hospital from 4 p.m. to 12 at midnight. The exact procedure for collecting data was agreed upon in advance. All questions were answered under supervision of the data collectors.

Distribution of the questionnaires and interviews took place in the waiting room of the pediatric emergency room prior to seeing the doctor. The adult was given the self-administered questionnaire and asked not to interfere with the child's interview, which took place at the same time. While the adult was completing the questionnaire, the child was asked in Arabic what was wrong with him or her and whether or not he/she could point to the site of current pain with the index finger. If the pain was localized, it was marked on the body diagram in the questionnaire form for the child and it was recorded that the child could identify the site of pain. Then, the child was asked to describe the intensity of the pain in his/her own words. The exact words used by the child were written down. The words were then translated from Arabic into English in consultation with the Head of the English Department in the Faculty of Medicine.

Finally, the Faces Pain Scale was explained to the child in the following manner: 'Each face is for a person who feels happy because he has no pain (hurt) or sad because he has some or a lot of pain: face 0 is very happy because it doesn't hurt at all; face 1 hurts just a little bit; face 2 hurts a little more; face 3 hurts even more; face 4 hurts a whole lot, and face 5 hurts as much as you can imagine, although you don't have to be crying to feel this bad'. The child was told to choose the face that best described how he/she was feeling, and it was marked on the questionnaire. At the end, the questionnaire for adults was checked and if some answers were missing and/or some questions not understood, the issues were clarified.

\section{Data Analysis}

All collected data were recorded and analyzed using the Statistical Package for the Social Sciences (SPSS) version 12.0, on a personal Intel-based computer. Data were checked and cleaned for possible mistakes.

Data were recoded and put in appropriate subgroups of gender, nationality, area of residence, birth order, total number of siblings and parental level of income and education in order to facilitate analysis. Using the adult's questionnaire, nationality was grouped as follows: Gulf Arabs (Kuwait and Kingdom of Saudi Arabia), Egypt and Levantine, Lebanese, Syrian, Jordanian and Palestinian. The area of residence, covered by each hospital, was included in the parameters of family characteristics as urban (Al-Amiri and Mubarak Al-Khabeer), semi-urban (Al-Adan and Al-Farwaniya), and rural (Al-Jahra).

Regarding the site of pain in the child's questionnaire, the abdomen, pelvis and loins, as well as upper and lower limbs were merged together. Descriptions of pain were grouped according to the following terms: hurt, sensation, pressure, and function (mobility). 
Descriptive frequency distributions as well as measures of location and dispersion (mean, SD, median) were obtained for all quantitative variables. The Student $t$ test was used to study the relationship between quantitative variables and binary qualitative variables. The $\chi^{2}$ test was used to study the relation between qualitative variables, and if one was binary, the linear-by-linear association was applied. Kappa statistics was applied as a measure of agreement between the children's and adults' assessment of pain intensity. The level of significance was $\mathrm{p}<0.05$.

\section{Results}

For the most part, parents (94\%) were the adults who accompanied children to the emergency room; for boys it could be either the father or mother, but for girls it was mostly the mother. Other adults who accompanied the sick child were grandparents, uncles, aunts, and siblings. About two thirds of the children had experienced pain in the previous year, mostly 1-2 times; boys had a maximum of 20 pain experiences and girls up to 12 . Regarding children's own assessment of current pain intensity, the mean for boys was 6.46 and for girls 6.75 .

Pain descriptions for both boys and girls are given in table 1. 'It hurts' and 'it hurts a lot' followed by 'a burning sensation' were the most frequently used words to describe the pain by both boys $(48,34.5 \%)$ and girls $(66$, $46.5 \%)$. Children with no past pain experience had a higher estimation of current pain when compared to those who had experienced pain in the previous year, whether categorized as 1-2 times or 3 times and above, or grouped together and observed in a dichotomous manner (as pain/no pain). The past experience of pain was statistically significant for boys $(\mathrm{p}=0.021)$ but not for girls $(\mathrm{p}=0.811)$.

The children's characteristics and pain scale ratings are given in table 2 . The pain rating was generally at the higher end of the scale with 6 and 8 as the highest rating of the children. Most of the younger children (6-8 years old) rated pain intensity at the extreme ends of the scale with the highest frequency at 8 . The older (9-12 years old) children's ratings were more in the middle of the scale, with the highest frequency at 6 . The difference was statistically significant $(\mathrm{p}=0.016)$. Children did not differ in self-reported pain intensity by nationality. Generally, the firstborn children tended to report lower intensity of pain than the fourth-born children and above. Whereas 13.4 and $23.4 \%$ of the first-born children reported pain intensity of 2 and 4 , respectively, only 3.7 and $12.9 \%$ of the fourth-born children and above reported pain intensity of 2 and 4, respectively. The difference was highly statistically signifi-
Table 1. The most common pain descriptions

\begin{tabular}{lcc}
\hline Parameter & $\begin{array}{l}\text { Boys } \\
(\mathrm{n}=139)\end{array}$ & $\begin{array}{l}\text { Girls } \\
(\mathrm{n}=142)\end{array}$ \\
\hline $\begin{array}{l}\text { Pain } \\
\quad \text { It hurts }\end{array}$ & $30(21.6)$ & $39(27.5)$ \\
$\quad$ It hurts a lot & $18(12.9)$ & $27(19.0)$ \\
Sensation & $17(12.2)$ & $16(11.3)$ \\
$\quad$ Burning & $8(5.8)$ & $7(4.9)$ \\
$\quad$ I feel like tingles & $9(6.5)$ & $7(4.9)$ \\
Function & $10(7.2)$ & $10(7.0)$ \\
$\quad$ I can't swallow & & \\
$\quad$ I can't breathe & $6(4.3)$ & $5(3.5)$ \\
Pressure & $5(3.6)$ & $5(3.5)$ \\
$\quad$ Cramping & & \\
\hline
\end{tabular}

Figures in parentheses indicate percentages.

cant $(\mathrm{p}=0.001)$. There was a highly significant difference between total number of siblings, as grouped in the table, and the intensity of pain rated by the child. However, there was no consistent pattern. When the number of siblings was observed in a dichotomous manner, children with up to 3 siblings reported significantly less intense pain compared to those with 4 and more siblings $(\mathrm{p}=0.035)$.

Family characteristics are cross-tabulated by pain intensity assessments of the child as in table 3 . The $\chi^{2}$ test showed statistically significant differences for all variables: area of residence $(\mathrm{p}=0.008)$, family income $(\mathrm{p}=$ $0.013)$, mother's $(p=0.001)$ and father's $(p=0.015)$ educational levels. Children from semiurban areas tended to choose extremes of the pain scale, while those from rural areas chose the middle scale. Children from families with intermediate family income scored lower compared to others.

A cross-tabulation of location of most pain according to the words used by children to describe the pain is given in table 4. Most children described neck pain as sensation. 'Hurts' is the word used for abdominal pain, whereas head, chest, and limb pain was described as pressure. These findings hold true for either boys or girls. All differences were highly statistically significant $(\mathrm{p}=0.0001)$. More girls complained about pain in the abdomen, pelvis and loins than boys, but boys complained more about pain in the limbs than girls.

The degree of agreement between the children's and the accompanying adults' assessment of pain intensity was extremely low (kappa $=0.038)$. The overall agreement rate between children and adults was only $28.8 \%$. 
Table 2. Characteristics of the children and their pain ratings

\begin{tabular}{|c|c|c|c|c|c|c|c|}
\hline \multirow[t]{2}{*}{ Variable } & \multicolumn{6}{|c|}{ Child pain scale } & \multirow{2}{*}{$\begin{array}{l}\mathrm{p} \text { value } \\
\left(\chi^{2} \text { test }\right.\end{array}$} \\
\hline & 2 & 4 & 6 & 8 & 10 & total & \\
\hline \multicolumn{8}{|l|}{ Age } \\
\hline Young (6-8 years) & $10(6.7)$ & $19(12.4)$ & $42(27.4)$ & $56(36.6)$ & $26(17.0)$ & $153(54.4)$ & \\
\hline Older ( $9-12$ years) & $6(4.6)$ & $31(24.2)$ & $45(35.1)$ & $33(25.8)$ & $13(10.1)$ & $128(45.6)$ & 0.016 \\
\hline Egyptian & $1(2.6)$ & $8(20.5)$ & $21(53.8)$ & $1(2.6)$ & $8(20.5)$ & 39 (13.9) & \\
\hline Levantine & $2(6.7)$ & $4(13.3)$ & $8(26.6)$ & $11(36.7)$ & $5(16.6)$ & $30(10.7)$ & 0.606 \\
\hline \multicolumn{8}{|l|}{ Birth order } \\
\hline 1 & $9(13.4)$ & $16(23.4)$ & $20(29.8)$ & $10(14.9)$ & $12(17.9)$ & $67(23.8)$ & \\
\hline $2-3$ & $3(2.8)$ & 20 (18.9) & $26(24.5)$ & $40(37.7)$ & $17(16.0)$ & $106(37.8)$ & \\
\hline $5-6$ & $4(5.8)$ & $14(20.3)$ & $24(34.8)$ & $19(27.5)$ & $8(11.6)$ & $69(24.6)$ & \\
\hline 7 and above & $1(1.7)$ & $3(5.2)$ & $21(36.2)$ & $30(51.7)$ & $3(5.2)$ & $58(20.6)$ & 0.002 \\
\hline
\end{tabular}

Arabian Gulf = Kuwaiti, Saudi Arabian Bedouin; Levantine = Lebanese, Syrian, Palestine. Figures in parentheses indicate percentages.

Table 3. Family characteristics by pain scale of the child

\begin{tabular}{|c|c|c|c|c|c|c|c|}
\hline \multirow[t]{2}{*}{ Variable } & \multicolumn{6}{|c|}{ Child pain scale } & \multirow{2}{*}{$\begin{array}{l}\mathrm{p} \text { value } \\
\left(\chi^{2} \text { test }\right)\end{array}$} \\
\hline & 2 & 4 & 6 & 8 & 10 & total & \\
\hline \multicolumn{8}{|l|}{ Area of residence } \\
\hline Urban & $6(6.3)$ & $21(22.1)$ & $29(30.5)$ & $23(24.2)$ & $16(16.8)$ & $95(33.8)$ & \\
\hline Semiurban & $9(7.8)$ & $20(18.2)$ & $31(26.7)$ & $35(30.2)$ & $21(18.1)$ & $116(41.3)$ & \\
\hline$<500 \mathrm{KD}$ & $6(9.8)$ & $6(9.8)$ & $15(25.6)$ & 17 (27.9) & $17(27.9)$ & $61(21.7)$ & \\
\hline $500-1,000 \mathrm{KD}$ & $8(5.4)$ & $29(19.6)$ & $51(34.5)$ & $45(30.4)$ & $15(0.1)$ & $148(52.7)$ & \\
\hline$>1,000 \mathrm{KD}$ & $2(2.8)$ & $15(20.8)$ & $21(29.2)$ & $27(37.5)$ & $7(9.7)$ & $72(25.6)$ & 0.013 \\
\hline \multicolumn{8}{|l|}{ Mother's educational level } \\
\hline No formal education & $1(1.6)$ & $1(1.6)$ & $19(13.1)$ & $34(55.7)$ & $6(9.8)$ & $61(21.7)$ & \\
\hline \multicolumn{8}{|l|}{ Father's educational level } \\
\hline No formal education & $1(8.3)$ & $0(0.0)$ & $1(8.3)$ & $7(58.3)$ & $3(25.0)$ & $12(4.3)$ & \\
\hline Primary & $3(6.8)$ & $3(6.8)$ & $12(27.3)$ & $22(50.0)$ & $4(9.1)$ & $44(15.7)$ & \\
\hline Secondary & $4(6.0)$ & $12(17.9)$ & $21(31.3)$ & $19(28.4)$ & $11(16.4)$ & $67(23.8)$ & \\
\hline $\begin{array}{l}\text { Diploma/University and } \\
\text { higher }\end{array}$ & $8(5.1)$ & $35(22.2)$ & $53(33.5)$ & $41(26.0)$ & $21(13.2)$ & $158(56.2)$ & 0.050 \\
\hline
\end{tabular}

Figures in parentheses indicate percentages. 
Table 4. Location of most pain by children's verbal description

\begin{tabular}{llllll}
\hline $\begin{array}{l}\text { Verbal } \\
\text { description } \\
\text { of pain }\end{array}$ & Gender & Site of pain & & $\begin{array}{l}\text { p value } \\
\left(\chi^{2} \text { test }\right)\end{array}$ \\
\cline { 2 - 5 } & & neck & $\begin{array}{l}\text { abdomen and } \\
\text { pelvis }\end{array}$ & $\begin{array}{l}\text { other (head, } \\
\text { chest, limb) }\end{array}$ & total \\
\hline Hurts & boys & $9(13.8)$ & $31(47.7)$ & $25(38.5)$ & $65(23.1)$ \\
Sensation & girls & $6(7.8)$ & $47(61.0)$ & $24(31.2)$ & $77(27.4)$ \\
Function & boys & $16(51.6)$ & $5(16.1)$ & $10(32.3)$ & $31(11.0)$ \\
& girls & $14(46.7)$ & $11(36.7)$ & $5(16.7)$ & $30(10.7)$ \\
Pressure & boys & $10(34.5)$ & $1(3.4)$ & $18(62.1)$ & $29(10.3)$ \\
& girls & $10(43.5)$ & $3(13.0)$ & $10(43.5)$ & $23(8.2)$ \\
& boys & $0(0.0)$ & $3(23.1)$ & $10(76.9)$ & $13(4.6)$ \\
\end{tabular}

Figures in parentheses indicate percentages.

Both measurements were also low when gender was analyzed separately; for boys, kappa was 0.082 with an overall agreement rate of $30.9 \%$, and for girls it was 0.005 , with an overall agreement rate of $26.1 \%$.

\section{Discussion}

The choice of the emergency room for data collection afforded the following advantages: data collectors avoided the effect of medication on the children as that would have altered the intensity as with patients in hospital wards; the psychological effect of such a medical intervention was therefore avoided; a large number of children attend the emergency department with different causes of pain.

Age distribution among children in our study was similar. The majority of the children were Kuwaitis, followed by Egyptians and Levantine nationalities. All of them were native Arabic-speaking children, but they used different expressions with the same word meanings. A total of 23 words grouped into four major categories were used. There was a problem in grouping Arabic words according to their corresponding English meanings. A wide variety of Arabic words is available for describing different aspects of pain [9]. Because of the formal separation in Arabic between the written and spoken forms of the language, different terms might be used and imperfectly understood. Harrison [9] found around $100 \mathrm{Ar}-$ abic words used by adults to describe pain. As children have limited language skills, the children in our study used 23 Arabic words to describe their pain. Some words

Assessing Children's Verbalization of Pain were exclusively used by children. The children also tried to explain their pain by behavior or describing their disability. Polkki et al. [3] in Finland have identified a problem of immature language skills among school-aged children. As a consequence of being common and simple to use, 'hurts' was the most frequently used word. Younger children tend to choose only the word 'hurts' or describe their pain by behavior and disability because of even more limited language skills and experience.

The abdominal and pelvic areas were the most common sites of pain, probably reflecting the high frequency of gastroenteritis [10] and urinary tract infections [11] in pediatrics. Neck pain was the second most common, mostly due to sore throat being a consequence of common upper respiratory tract infections. Boys were 3 times more prone to limb pain, probably because of a higher frequency of injuries.

Parents were the accompanying adults for most of the participants; boys were brought to the emergency department by their mother and father equally, while girls were brought by their mother twice as frequently as boys reflecting the closer association between mothers and girls, as girls prefer to complain about their pain to their mother in rural and semirural areas. However, the cultural norm is that the father takes the child to the hospital rather than the mother.

Younger children tended to estimate their pain at the extremes of the pain scale, whereas older children opted more for middle values. This significant difference might be explained by cognitive development and intelligence as the child matures, as shown in studies in Taiwan [1] and Finland [3]. However, a study in Canada [12] did not 
show any difference in pain assessment for children aged 5-12 years.

First-born children reported a lower level of pain than others, as the first child is raised to be strong and responsible. The more siblings the child had, the higher the rating of pain on the scale, possibly attributable to the child seeking parental attention.

Sociodemographic characteristics of the children played a role in the child's estimation of pain. Children from families with a low total monthly income estimated their pain as more intense than those with a higher family income. This could be due to neglect or psychological factors. Children of more educated parents scored pain as being of lower intensity, which might be a reflection of how educational level changes the perception and attitude of children. It is therefore important that cultural factors, child care and rearing, as well as health-related practices and behavior be taken into account as well described by Zahr and Hattlar-Pollara [13] when assessing pain intensity.

A major finding of the present study was the poor agreement between the adult's and child's assessment of pain, which was very similar to previous reports $[9,14$,
15]. However, a study in Canada [12] showed a higher correlation between parents' and children's estimation of pain. Unfortunately, if there is poor agreement between children's and parents' pain ratings, it is unclear which assessment is the better approximation of the true degree of pain that the child is experiencing, as pointed out by Singer et al. [16]. We think that the child is the better source of his/her own pain because pain is a personal feeling, and children of school age have the ability to express pain and measure its intensity.

\section{Conclusion}

This study shows that the children were able to describe their current pain in their own words, localize the site of most pain and rate its intensity. The most frequent and highest intensity of pain reported was in the abdominal region. Intensity of pain was associated with birth order, higher number of siblings, and lower number of previous pain episodes. Finally, there was no agreement in the assessment of pain intensity between parents and children.

\section{References}

$>1$ Cheng SF, Foster RL, Hester NO, Huang CY: A qualitative inquiry of Taiwanese children's pain experience. J Nurs Res 2003;11:241250.

2 Gharaibeh M, Abu-Saad H: Cultural validation of pediatric pain assessment tools: Jordanian perspective. J Transcult Nurs 2002; 13:12-18.

7 Polkki T, Pietila AM, Rissanen L: Pain in children: qualitative research of Finnish school-aged children's experiences of pain in hospital. Int J Nurs Pract 1999;5:21-28.

4 Ramritu PL: Use of Oucher numeric and the ward graphic scale in children aged 9-14 years with post-operative of pain. J Clin Nurs 2000;9:763-773.

5 Gagnon TSL, Bonnin ACB, Villeneuve E: Pain evaluation in preschool children and by their parents. Acta Paediatr 1999;88:422427.
6 Wong D, Baker C: Wong on web. Young children pain and faces. 1991. http://www3.us. elsevierhealth.com $\backslash W O W \backslash$ fyi03.html (accessed April 4, 2005).

7 Luffy R, Grove SK: Examining the validity, reliability and preference of three pediatric pain measurement tools in African-American children. Pediatr Nurs 2003;1:54-59.

8 Trai T, Yukioka H, Asada A: Pain evaluation in the intensive care unit: Observed-reported faces scale compared with the self-reported visual analog scale. Reg Anesth Pain Med 1998;2:147-151.

$\checkmark 9$ Harrison A: Arabic pain words. Pain 1988; 38:239-250.

10 Leung AK, Sigalet DL: Acute abdominal pain in children. Am Fam Physician 2003;67: 2321-2326.
11 Radzik D, Bua J, Marchetti F: Opiates and acute abdominal pain. JAMA 2007;297:467468.

12 Chambers CT, Giesbrecht K, Craig KD, Bennett SM, Huntsman E: A comparison of faces scales for the measurement of pediatric pain: children's and parents ratings. Pain 1999;1: 25-35.

13 Zahr LK, Hattlar-Pollara M: Nursing care of Arab children: consideration of cultural factors. J Pediatr Nurs 1998;6:349-355.

14 Kelly AM, Powell CV, Williams A: Parent visual analogue scale ratings of children's pain do not reliably reflect pain reported by child. Pediatr Emerg Care 2002;3:159-162.

15 Harrison A, Badran S, Ghalib R, Rida S: Arabic children's pain descriptions. Pediatr Emerg Care 1991;4:199-203.

16 Singer AJ, Gulla J, Thode HC Jr: Parents and practitioners are poor judges of young children's pain severity. Acad Emerg Med 2002; 9:609-612. 